\section{Molecular biology of ghosts}

SIR - Daedalus's explanation of ghosts (Nature 372, 324; 1994) is manifestly untenable, and it is perhaps appropriate to propose a more plausible hypothesis.

Most ghostly apparitions are of people who have died from relatively violent causes: shootings, decapitation, burning and so on. These traumas would release the contents of many cells into the atmosphere, including fragments of nucleic acids (molecules which, as fossil studies have illustrated, are relatively stable over long periods of time). My proposal is that some of these nucleic acids could behave as viral particles ('viricles'). They could enter the bodies of living individuals either via the lungs, thus gaining access to somatic cells, or via the olfactory mucosa, gaining direct access to the brain. In either case the viricles would multiply within the living body. Many sightings of ghosts occur in or near churchyards or cemeteries, raising the possibility that as the cell contents of interred (carrier) individuals are brought to the soil surface, viricles from their cells and their antecedents will again be released into the atmosphere, perpetuating the cycle.

Consider an individual arriving at or near the scene of a violent death and inhaling a population of viricles. Over a period of minutes to years, depending on the viral load in the atmosphere and its infectivity, the viricle will gain access to phylogenetically old regions of the olfactory system including the hippocampus, an area widely accepted to be the seat of memory and associated physiological processes such as long-term potentiation. (Fast axonal transport at $400 \mathrm{~mm}$ per day will convey the viricle from the nose to the hippocampus in around 5 hours.)

As long-term memories are believed to be stored in the hippocampus as modified proteins, proteins produced by the intruder viricle may rapidly enter the 'memory banks' of the carrier. A triggering stimulus (for example, entering a relevant room) may then initiate a brief sequence of recall coded by the viricle. The sequence would be translated by the brains of most individuals into a third person apparition. However, it is worth considering that if the individual is susceptible enough to accept the viricular information as selfgenerated, this same sequence would yield sensations of reincarnation.

\section{T.W. Stone}

Institute of Biomedical and Life Sciences, University of Glasgow, Glasgow G12 8QQ, UK

SIR - Daedalus speculates on the link between our realm and that of the phantoms (Nature 372, $226 \&$ 324; 1994). His principal conclusion is that ghosts are simply spirits kinetically trapped in a transition region by the cold of the other side. He offers some practical suggestions when handling the dead to avoid soul trapping, such as cremation and microwave-oven use during final rites. The implications are heartening for those planning to freeze themselves cryogenically near the end of life - they can hope for a re-animation that will successfully unite body with spirit, the latter having been efficiently "tied down" by a bath in liquid nitrogen. We recommend that everyone visit his or her cryocentre well before the final events of life, however, to ensure that the staff cafeteria is located a safe distance from the mummies.

Frederick Fenter

Françols Caloz

Laboratory for Soil and Air Pollution, Swiss Federal Institute of Technology, 1015 Lausanne, Switzerland

\section{Wrong move}

SIR - It was announced last November that Hoffmann-La Roche is to close the Roche Institute of Molecular Biology (RIMB) in Nutley, New Jersey (see $\mathrm{Na}$ ture 373, 94; 1995). Although the institute will be relocated on the campus of Syntex in Palo Alto, California, it is apparent that the RIMB will continue to exist in name only, as the mission of the transplanted institute will focus on genomics and the sequencing of the human genome, efforts that are now in vogue. As it seems unlikely that any members of the 160 -person staff will be asked to move to the new location, the current staff must relocate, retire or find new positions.

We view these events with great sadness, most importantly because they occur at a time when support for basic research is dwindling. The RIMB has been unique since its inception in 1967 when it became the first institution devoted entirely to basic research supported by a pharmaceutical company. Initially, there was considerable scepticism in the scientific community about Hoffmann-La Roche's commitment. But with Roche's generous support, the institute attracted a number of excellent scientists and soon attained a world-class reputation which has been maintained for over 25 years. On the basis of most recent citation indexes, for instance, the RIMB ranks remarkably high. In addition, the institute has played an important role in training outstanding scientists, many of whom now occupy positions in academic institutions and industry throughout the world. With the help of the institute, Hoffmann-La Roche Inc. was one of the first pharmaceutical companies to use molecular biology in drug development, thereby making it a standard-bearer in the industry. Moreover, the development and marketing of Abuscreen and $\alpha$-interferon stemmed directly from the research of institute scientists. The RIMB is unique and has succeeded in its mission in research and training to an extent that exceeded expectations. As our understanding of the molecular biology of cellular processes is far from exhausted, it is difficult to understand Hoffmann-La Roche's decision to close the RIMB in Nutley.

For the current members of the RIMB, this closure represents a personal loss and a feeling of abandonment by HoffmannLa Roche, to which they committed themselves and their careers. For the larger scientific community, it represents yet another loss in support for the kind of fundamental research that is essential for scientific progress but for which there is no vocal public constituency.

Christlan Anfinsen, Jullus Axelrod, Paul

Berg, Allan Conney, Bernard Horecker, Ronald Kaback*, Arthur Kornberg, Joshua Lederberg, Marshall Nirenberg, George Palade, Sidney Pestka, Premkumar Reddy, Aaron Shatkin, Ann Skalka, Sidney Specter, Arthur Weissbach *HHMIResearch Laboratories, University of California, LosAngeles,

California 90024-1662, USA

\section{Marconi minute}

SIR - At the beginning of this century, Guglielmo Marconi developed wireless communication. If he had not done so, television, computers and many other miracles of this electronic age might never have been invented.

The celebration of the Millennium coincides with the centenary of Marconi's most important experiments.

To commemorate these two important events, I would like to construct a replica of the equipment that Marconi used to transmit the first radio signal across the Atlantic Ocean and then repeat his experimental transmission at the Millennium.

At this time I would like there to be one minute of radio silence throughout the world, when every possible item of radio and electronic equipment is turned off. This would be called the "Marconi Minute". This should enable scientists, especially astronomers, to detect very faint sources of radio signals that are at present obscured.

The Marconi Minute could be signified by transmitting the letter $\mathrm{S}$ in morse code at the beginning and end of the minute, on the replica equipment.

\section{H. C. Alexander}

11 St John's Drive,

North Rigton.

Leeds LS17 OHD, UK 